\title{
Sitting comfort and discomfort and the relationships with objective measures
}

\author{
Michiel P. De Looze $\dagger^{*}$, Lottie F. M. KuiJt-Evers $\dagger$ and JaAp van DieËn \\ $\dagger$ TNO Work and Employment, P.O. Box 718, 2130 AS Hoofddorp, \\ The Netherlands \\ †Faculty of Human Movement Sciences, Vrije Universiteit, Amsterdam, \\ The Netherlands
}

Keywords: Comfort; Discomfort; Sitting; Pressure distribution.

\begin{abstract}
The concepts of comfort and discomfort in sitting are under debate. There is no widely accepted definition, although it is beyond dispute that comfort and discomfort are feelings or emotions that are subjective in nature. Yet, beside several subjective methodologies, several objective methods (e.g. posture analysis, pressure measurements, electromyography (EMG) are in use to assess sitting comfort or discomfort. In the current paper a theoretical framework is presented, in which comfort and discomfort were defined and the hypothetical associations with underlying factors were indicated. Next, the literature was reviewed to determine the relationships between objective measures and subjective ratings of comfort and discomfort. Twenty-one studies were found in which simultaneous measures of an objective parameter and a subjective rating of comfort or discomfort were obtained. Pressure distribution appears to be the objective measure with the most clear association with the subjective ratings. For other variables, regarding spinal profile or muscle activity for instance, the reported associations are less clear and usually not statistically significant.
\end{abstract}

\section{Introduction}

In Western societies, the end user comfort of products has developed into an important issue, not only recognized by the end users themselves. Producers recognize comfort as a major selling point, as it is thought to play an increasingly important role in product-buying decisions. Also, employers are getting interested in comfortable equipment for their employees in order to create a healthy and stimulating working environment.

End user comfort of products is also well-addressed in the ergonomics literature. One of the products often considered is the seat. Evaluative studies on sitting comfort are numerous and mainly concerned with office seats (e.g. Bendix et al. 1985, van Dieën et al. 2001), passenger seats in public transport (e.g. Zhoa and Tang 1994) and operator seats in cars, buses, and harvesting machines (e.g. Mehta and Tewari 2000).

The frequent references to sitting comfort suggest that it represents a consensually held construct. Yet, there is no widely accepted definition of comfort nor sitting

*Author for correspondence. e-mail: m.dlooze@arbeid.tno.nl 
comfort (Lueder 1983, Helander and Zhang 1997). Specifically, comfort and discomfort have been varyingly interpreted as either two extremes at a continuum or two different constructs with different sets of underlying factors.

Moreover, many different methods are in use to measure sitting comfort and discomfort, which further complicates a universal understanding of the concept. Roughly, two types of measurement methods can be discerned. First, various subjective methods ('directly asking people about how comfortable they are') are in use. This methodology can be regarded as the most direct, considering that comfort or discomfort is a subjective state or feeling (Richards 1980). Objective methods (e.g. pressure distribution measurements, electromyography or posture analysis) may have some advantages as compared to subjective methods: less time consuming, requiring a smaller number of subjects, less prone to measurement error or bias, and applicable earlier in the design process (Lee et al. 1993). On the other hand, objective methods to assess comfort are indirect. At best, they give an indication of an individual's sitting comfort, but actually, they do measure something else (e.g. pressure distribution, muscle activity or lumbar curvature). Only if correlations between objective measurements and sitting comfort are present, the objective methods can form a useful addition to subjective methods.

The aim of the present paper is twofold. First, it sets out to describe the nature of comfort and discomfort, and present these in a model showing the hypothetical relationships between comfort, discomfort and their underlying factors. Secondly, it seeks to establish the state of knowledge on the relationships of objective measures with comfort and discomfort. To this end, experimental studies on sitting comfort and discomfort were reviewed, in which both subjective and objective measures were applied. The intention of this paper is to discuss the potential to predict comfort or discomfort from objective methods.

\subsection{Definitions}

\section{Sitting comfort and discomfort}

Webster's Dictionary defines comfort as a state or feeling of having relief, encouragement and enjoyment. Slater (1985) defines comfort as a pleasant state of physiological, psychological and physical harmony between a human being and its environment. Richards (1980) stresses that comfort is a state of a person involving a sense of subjective well-being, in reaction to an environment or situation. In general, it could be said that comfort is not yet clearly defined, yielding an on-going debate in the literature (see Richards 1980, Lueder 1983, Bishu et al. 1991, Zhang et al. 1996 and Helander and Zhang 1997). Issues that are not under debate are: (1) comfort is a construct of a subjectively-defined personal nature; (2) comfort is affected by factors of a various nature (physical, physiological, psychological); and (3) comfort is a reaction to the environment.

The debate in the literature concentrates on the difference between comfort and discomfort. Several researchers have conceptualized comfort as two discrete states: comfort presence and comfort absence, where comfort has been simply defined as the absence of discomfort and vice versa. (Hertzberg 1958, Floyd and Roberts 1958). This implies that comfort does not necessarily entail a positive affect (Branton 1969) and that the ultimate goal of seat designers is reaching the state of absence of discomfort, where the working individual is oblivious of the fact that he or she is seated (Bishu et al. 1991). 
In contrast with the concept of two discrete states, many researchers and practitioners believe that comfort and discomfort are two opposites on a continuous scale, ranging from extreme discomfort through a neutral state to extreme comfort. This stems from the fact, that people frequently and naturally distinguish ordered levels of their subjective responses across the entire continuum from strongly positive to strongly negative (Richards 1980). The same principle underlies the graded scales (e.g. rating scale of Shackel et al. 1969), which have been used to evaluate seats.

Others have questioned the intuitive assumption of comfort/discomfort as a single dimension on a continuous scale. Several studies indicate that comfort and discomfort are affected by distinctly different variables (Kleeman 1981, Kamijo et al. 1982). In the study of Zhang et al. (1996), the identification of these variables was the primary goal. First, in a questionnaire survey, 104 respondents provided descriptors of the feelings they experienced when they felt comfortable (e.g. agreeable, at ease, calm) or discomfortable (e.g. fatigue, cramped, restless) in a seated workplace. Secondly, to validate these descriptors, another group of 34 participants was asked to rate these descriptors on a 5-points scale, from 'very closely related to comfort/discomfort' to 'not related at all'. After this analysis, 43 descriptors remained: 21 for discomfort and 22 for comfort. Thirdly, a classification analysis was performed, involving multi-dimensional scaling, factor-analysis and cluster-analysis, to statistically identify the factors related to comfort and discomfort. It was concluded that comfort and discomfort are based on independent factors. Feelings of discomfort are mainly associated with pain, tiredness, soreness and numbness. These feelings are assumed to be imposed by physical constraints and mediated by physical factors like joint angles, tissue pressure and circulation blockage. Comfort, on the other hand, is associated with feelings of relaxation and well-being (Zhang et al. 1996). In a later study (Helander and Zhang, 1997) involving 20 and 37 subjects respectively, this factor structure was confirmed. It was also observed that aesthetic design matters with respect to comfort, but not to discomfort. Moreover, low values of discomfort factor scores were associated with a full range of values of overall comfort ratings from 1 to 9 , while comfort ratings decreased sharply with increasing discomfort scores. This indicates that, when discomfort factors are present, comfort factors become secondary in the comfort/ discomfort perception (hence, discomfort has a dominant effect, Helander and Zhang 1997).

As a practical consequence of this theory, comfort and discomfort need to be treated as different and complementary entities in ergonomics interventions. Paul et al. (1997) propose the nurturing/pampering paradigm, indicating the need for different strategies for reducing discomfort (nurturing) and increasing comfort (pampering) in the work place.

\subsection{Theoretical model}

The different factors underlying sitting discomfort and comfort can be modelled as presented in figure 1 .

The left part of this theoretical model concerns discomfort. According to Zhang et al. (1996), physical processes underlie discomfort. Similarly to previous models on the aetiology of work-related physical complaints (Winkel and Westgaard, 1992; Armstrong et al. 1993), the authors consider 'exposure', 'dose', 'response' and 'capacity' as the main issues. According to Armstrong, exposure refers to the external factors producing a disturbance of the internal state (dose) of an individual. 


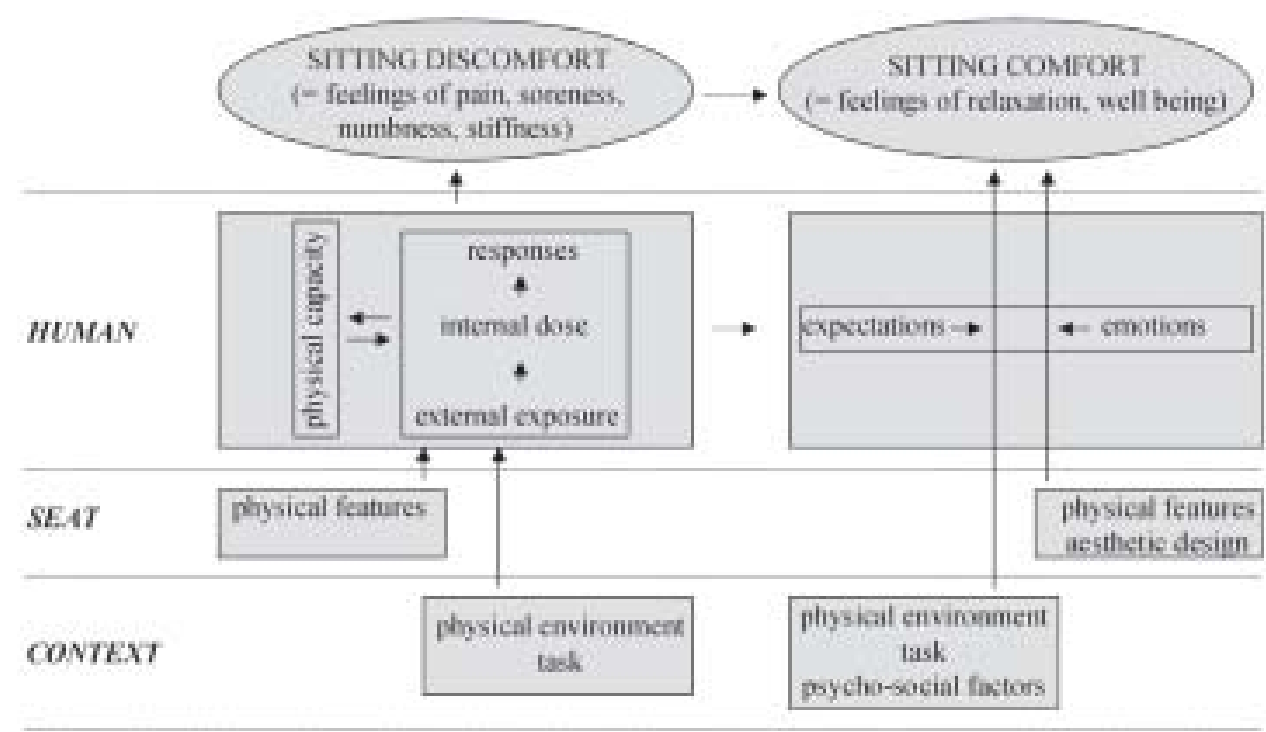

Figure 1. Theoretical model of comfort and discomfort and its underlying factors at the human, seat and context level.

The dose may evoke a cascade of mechanical, biochemical or physiological responses. The extent to which external exposure leads to an internal dose and responses, depends on the physical capacity of the individual. With regard to sitting, it could be said that the physical characteristics of the office seat (e.g. form, softness), the environment (e.g. table height) and the task (e.g. the performance of VDU activities) expose a seated person to loading factors, which may concern forces and pressure from the seat on the body and joint angles. These external loads may yield an internal dose in terms of muscle activation, internal force, intra-discal pressure, nerve and circulation inclusion, and skin and body temperature rise, provoking further chemical, physiological and biomechanical responses. By exterocepsis (stimuli from skin sensors), propriocepsis (stimuli from sensors in the muscle spindle, tendons and joints), interocepsis (stimuli from internal organ systems) and nocicepsis (stimuli from pain sensors), the perception of discomfort might be established.

The right part of the model concerns comfort, i.e. feelings of relaxation and wellbeing. Again, the influential factors are presented on a human, seat, and context level. At a context level, not only the physical features are assumed to play a role, but also psycho-social factors like job satisfaction and social support. At a seat level, the aesthetic design of a seat in addition to physical features may affect the feelings of comfort. At human level the influential factors are assumed to be individual expectation and other individual feelings or emotions. The dominant factor of discomfort, as suggested by Helander and Zhang (1997), is illustrated by the horizontal arrows pointing from the left (discomfort) to the right (comfort) part.

From this model it can be expected that for discomfort the relationships of objective measures with discomfort would be stronger than for comfort, as the link between discomfort objective measures of physical exposure, dose or response is more direct. 


\subsection{General}

\section{Relationships of objective measures to comfort and discomfort}

A literature search using the computerized systems NIOSHTIC, MEDLINE and Ergonomics Abstracts, isolated 21 studies, in which subjective (dis)comfort ratings and objective measures were simultaneously obtained.

The objective measures in these studies concern measurements of posture, number of body movements, estimations of muscle activation and muscle fatigue by electromyography (EMG), measurements of pressure at the back rest and seat pan, model-estimations of spinal loading forces, measurements of stature loss (spinal shrinkage) and foot volume change. The seats in these studies mainly concern office seats and car seats. Tables $1-4$ present an overview of these studies. Specifically, these tables outline the objective measure, the comfort or discomfort parameter under investigation, the study design, and the conclusion on the relationship between the objective measure and comfort or discomfort.

With respect to the subjective parameter, it is remarkable that most studies treat comfort/discomfort as one variable on one scale from extreme discomfort to extreme comfort, either on a local or a general level. The other studies evaluate local discomfort only. In none of the studies, comfort and discomfort has been separately determined on different scales.

\subsection{Posture and movement}

Five studies were found in which (dis)comfort ratings and some measure of posture or movement were simultaneously obtained. This measure concerns some measure of back posture (in three studies) and back and other movements (in one). In none of the studies was a significant correlation observed between comfort or discomfort and the parameter under investigation (table 1).

In four studies however, some associations seems to exist, for which no statistical evidence was provided. Eklund and Corlett (1987) compared two seats in five tasks and they observed that the seat with the most trunk flexion was always the seat with the most discomfort. Zhao and Tang (1994) studied the back posture in relation to the back rest of the seat. They report some, not-statistically supported, association of comfort with the quality of the spatial fit between the back and the back rest profile. A more detailed study on spinal profile (Bishu et al. 1991) points at various specific ranges for the various spinal angles under investigation, where discomfort is minimal. According to the authors the number of subjects was too small to find any statistical evidence. Variation in back posture was studied by Salewytsch and Callaghan (1999). They reported a trend towards a smaller range of lumbar spine postures in subjects with more discomfort. Also of importance is their final conclusion that there were no statistically significant postural deviations that distinguished between people that reported discomfort and those that did not.

\subsection{Electromyography}

No statistical relationships have been established between any measure of muscle activity and ratings of comfort or discomfort, except for one study (Lee et al. 1988). In this study the increase in back and shoulder muscle activation over time was significantly related to the increase of discomfort over time (table 2).

In five other studies, the correlation between EMG and (dis)comfort variations was studied across seat conditions and in some of these only some tendencies were observed. Remarkably, these tendencies concern an association of local discomfort 


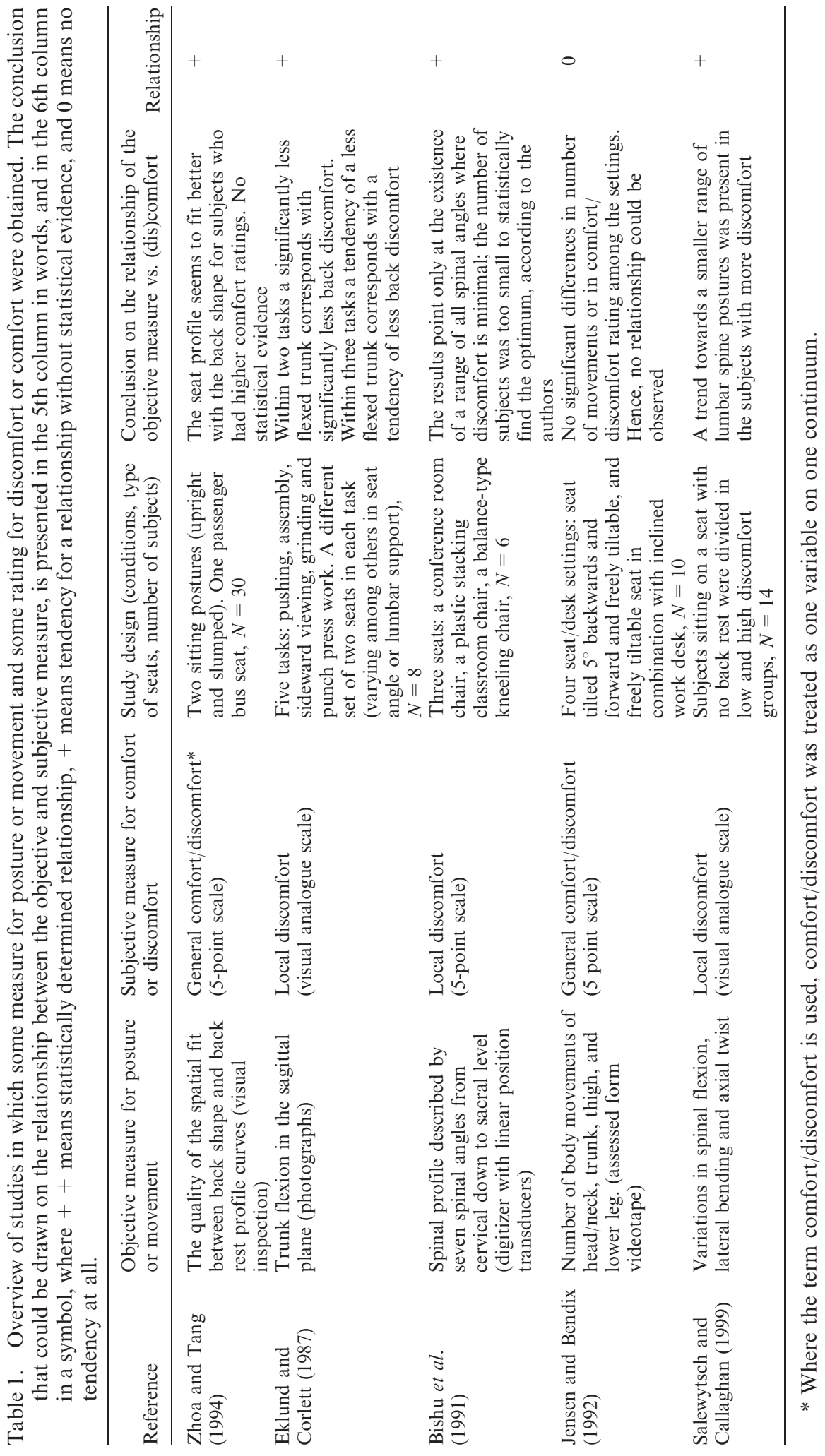




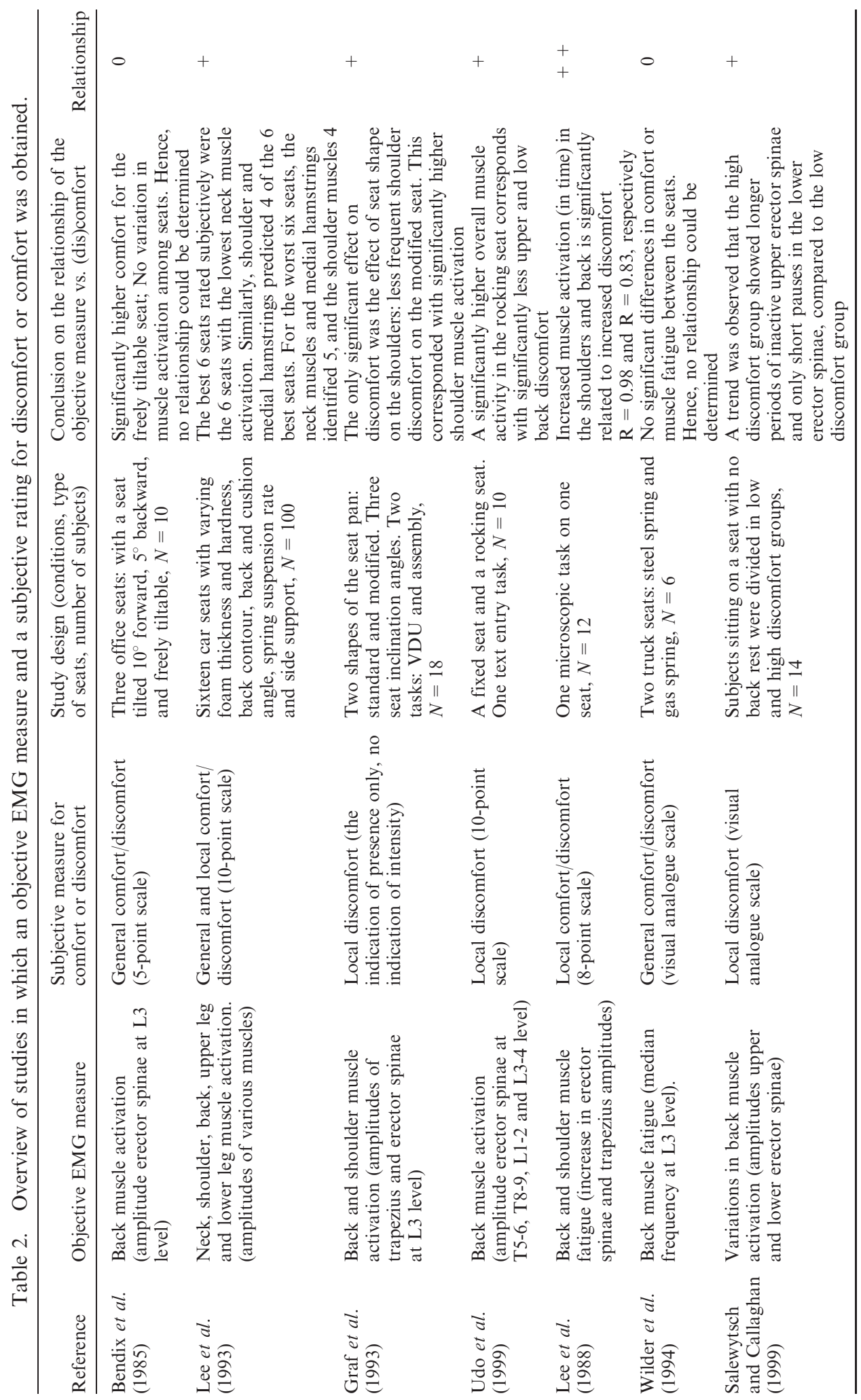




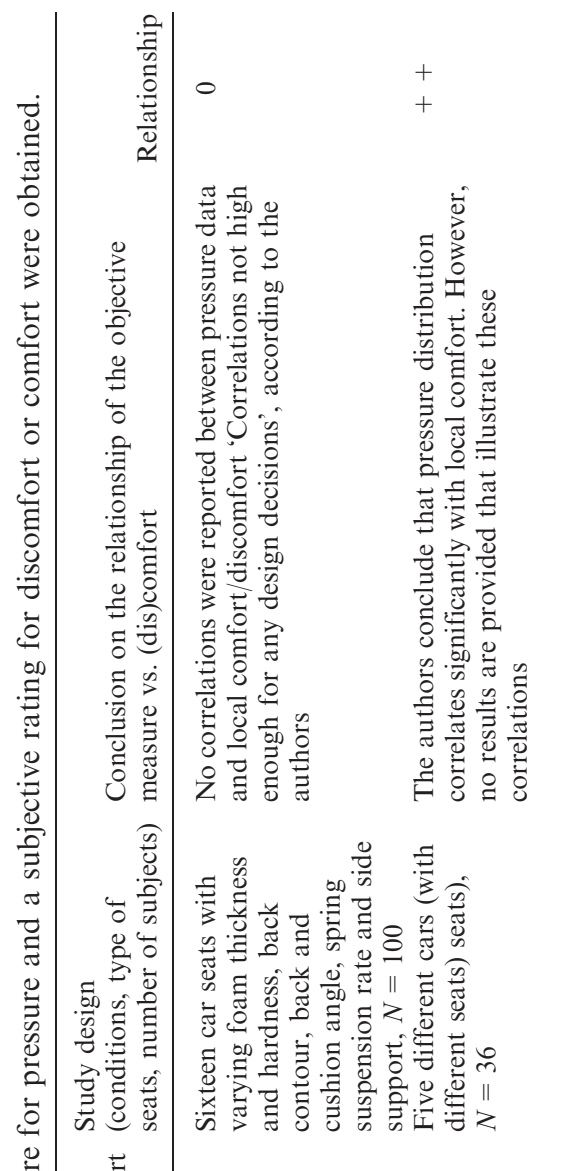

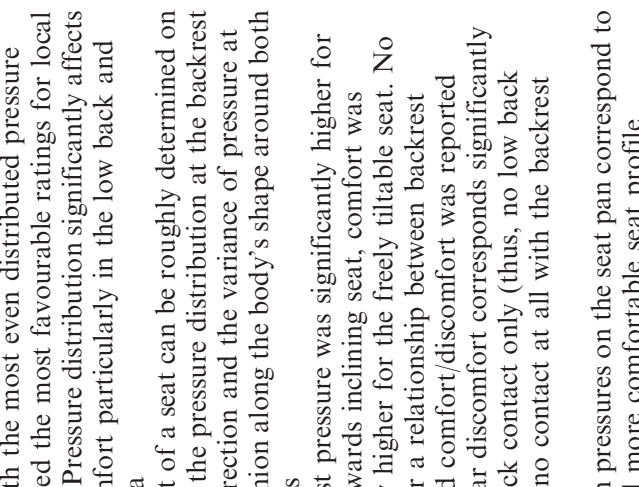

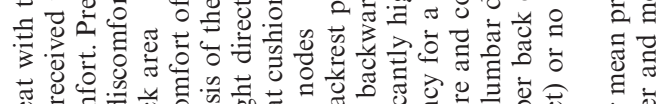

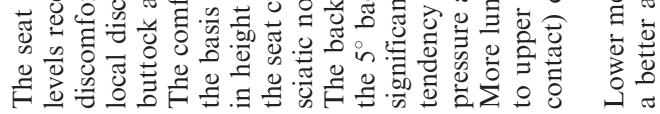

蒫

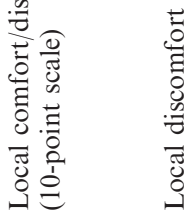

है

要.䓂

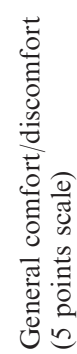

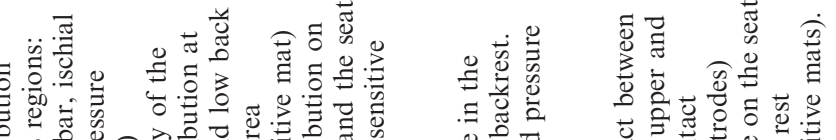

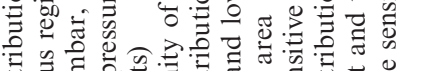

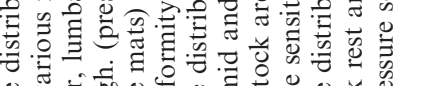

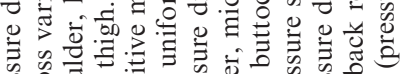

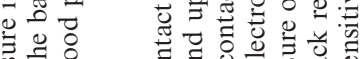

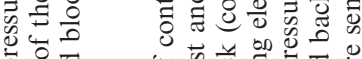

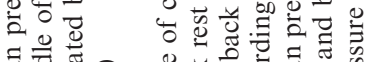

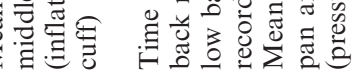

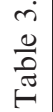

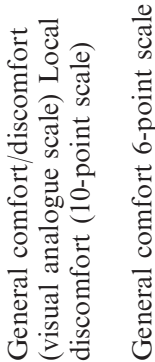

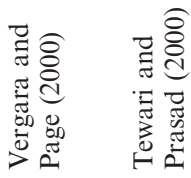

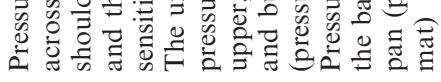

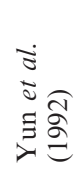

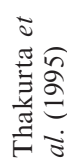

i

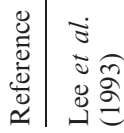

ปั่

㪨蜀 


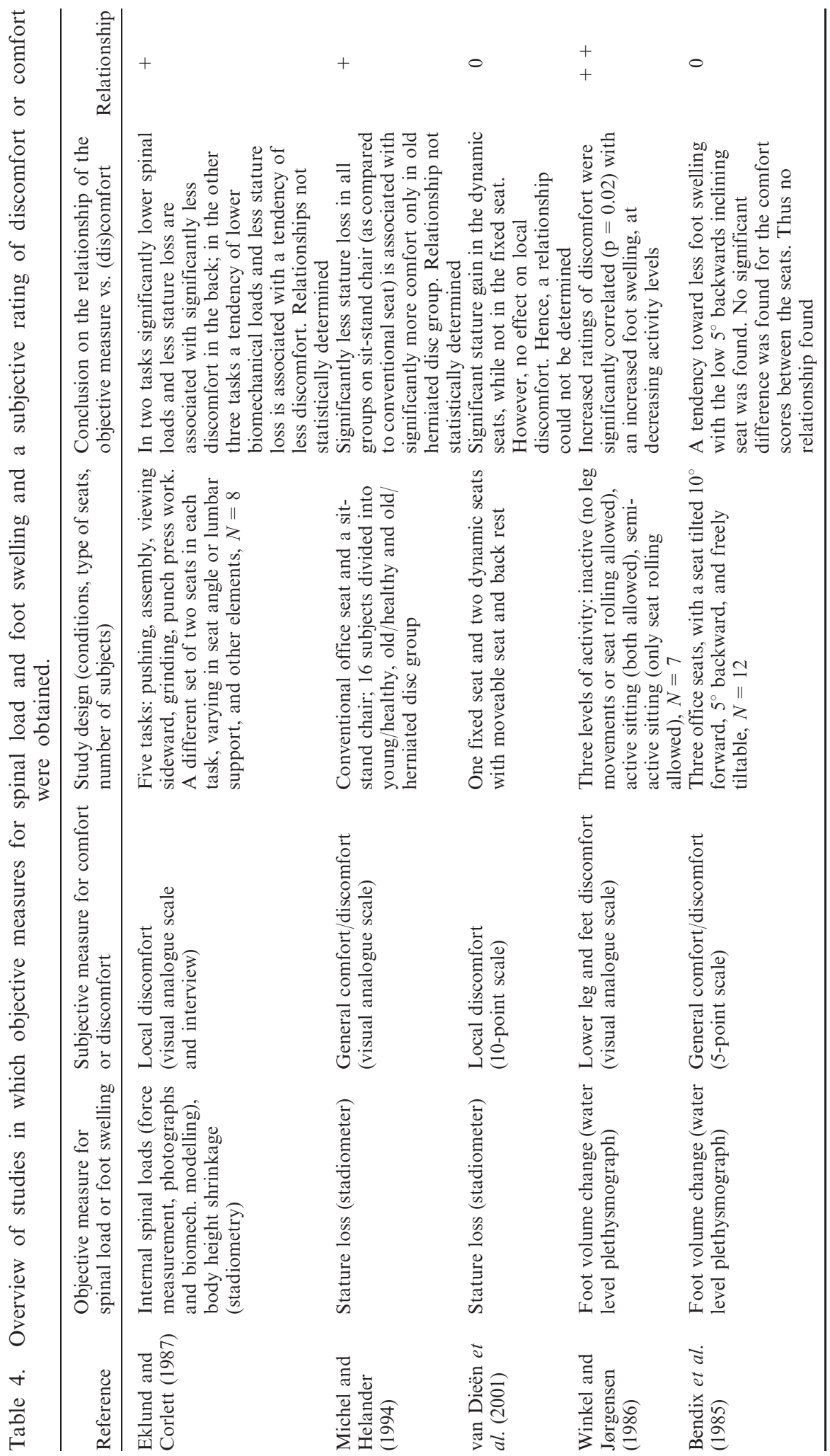


with both low and high EMG amplitudes. Probably, both high muscle activation fatiguing the muscle, and low and static muscle activity hampering muscle blood circulation would yield feelings of discomfort.

In one study, the median frequency of the EMG signals was used to determine back muscle fatigue. This study was too small (two conditions, six subjects) to draw any conclusion on the relationship with comfort or discomfort.

Salewytsch and Callaghan (1999) studying the variations in EMG amplitude in a low and high discomfort group also did not find significant results, but only a trend towards longer pauses in muscle activation for the upper erector spinae and shorter pauses for the lower erector spinae in the high discomfort group as compared to the low discomfort group.

\subsection{Pressure distribution}

Seven studies were found in which measurements of pressure at the back rest and/or seat pan could be compared with a comfort or discomfort rating (table 3). Significant correlations are reported from three studies (Yun et al. 1992, Thakurta et al. 1995, Vergara and Page 2000), while two other studies (Kamijo et al. 1982, Tewari and Prasad 2000) report associations (without statistical evidence).

However, some critical points should be raised. First, from the largest study by Lee et al. (1993) comprising 100 subjects and 16 seats, no association is reported. Lee et al. (1993) state that the correlations between pressure data and comfort were not high enough to be the basis for any design decision. In addition, the second largest study does report significant correlations (Thakurta et al. 1995), but the paper does not provide the information (e.g. on the statistical methodology, the level of significance, the strength of correlation, underlying results) required to interpret the relevance of this conclusion.

Yun et al. (1992), who do provide the required information, found that the uniformity of the pressure distribution, particularly at the low back and buttock area was statistically correlated to local discomfort in a study on car seats. In line with this, Kamijo et al. (1982), although not reporting statistical evidence, associate a comfortable car seat with a variance of pressure along the body's shape around both sciatic nodes. Moreover, for a car seat to be qualified as comfortable it seems to be important that it provides lumbar support. Specifically, comfortable seats are characterized by mean pressure levels of $1.4 \mathrm{kPa}\left(15 \mathrm{~g} / \mathrm{cm}^{2}\right.$ to $2.3 \mathrm{kPa}\left(24 \mathrm{~g} / \mathrm{cm}^{2}\right)$ in the lumbar region of the back rest, and by pressure levels of $5.8 \mathrm{kPa}\left(60 \mathrm{~g} / \mathrm{cm}^{2}\right)$ under the ischia and $2.9 \mathrm{kPa}\left(30 \mathrm{~g} / \mathrm{cm}^{2}\right)$ elsewhere (Kamijo et al. 1982).

The importance of lumbar support has also been found in office seats where the absence of low back contact with the back rest was found to be statistically correlated with low back discomfort by Vergara and Page (2000).

\subsection{Spinal load}

Simultaneous comfort recordings and spinal load estimations have been performed in three studies (table 4).

Eklund and Corlett (1987) measured the stature loss (as a measure of spinal load) and they estimated the spinal forces on the basis of force measurements and posture recording. In their comparison between two seats it was found that the seat with the lowest stature shrinkage an lowest spinal force was always the seat with the least discomfort. Similarly, a tendency towards less general discomfort at less stature loss was found by Michel and Helander (1994), but only in a specific subgroup of their 
subjects: 30 - 44 year old people with herniated discs. From the study of van Dieën et al. (2001) no relationship could be established as their conditions concerning dynamic and fixed seats were only discriminative for spinal shrinkage and not for local discomfort.

\subsection{Foot swelling}

Increased foot swelling (table 4) seems to be associated with less local discomfort in the lower leg and feet. This result however was obtained by a study design where conditions represent different levels of allowed activity and not different seats (Winkel and Jørgensen 1986). This implies that it remains questionable whether foot volume change is a useful measure, providing the seat designers with valid information on the comfort or discomfort of different seats. Bendix et al. (1985) who also measured foot volume changes, did not find any variation in general comfort/discomfort across three office seats, hence found no relationship with foot volume change.

\subsection{General considerations}

\section{Discussion}

The intention of this paper was to indicate whether objective measures are related to subjective feelings of comfort or discomfort. If found to be so, this could be helpful, in the evaluation and design processes of office seats, car seats, seats at home and so on. Objective methods seem to be advantageous compared to subjective methods with respect to issues regarding required time, number of subjects and reliability. For a general discussion on the scientific and practical value of subjective methods we refer to a review of Annett (2002). The combination of valid objective measures with subjective ratings of comfort and discomfort, may give support to seat designers. The question however is, what objective measures are related to comfort and discomfort. This firstly needs a clear definition of comfort and discomfort. Therefore a theoretical framework was presented defining comfort, discomfort and the hypothetical associations with underlying factors.

As discussed, it seems useful to make a distinction between comfort and discomfort, as the underlying constructs are different (Zhang et al. 1996). Helander and Zhang (1997) propose a checklist/questionnaire that directly addresses the underlying constructs (descriptors) for comfort and discomfort, resulting in separate ratings for comfort and discomfort on separate scales. In the studies reviewed, this approach has not been applied. Whether the Helander and Zhang's (1997) approach to rate comfort and discomfort would have led to other results remains questionable. Also, the expectation that discomfort is more closely related to objective physical measures as compared to comfort cannot be verified.

Another remark concerns the variety of the studies that were reviewed. First, the studies were highly variable with respect to number of subjects and the number of conditions. Secondly, the goals of the studies were different. Either, it was the primary goal to determine the relationship between the objective and subjective measure, or it was just a sub-goal, or the study obtains subjective and objective measures without the aim of finding the correlations. It was decided to include all these studies in the review, as all may contain valuable information. For the same reason it was decided, to not ignore the not statistically significant tendencies (indicate by + in the tables), for studies that were not aimed at determining a relationship may have been not optimally designed or no statistical effort might have 
been performed. Finally, the research conditions vary greatly among the various studies. In most studies, the various conditions represent different car or office seats. As the conditions determine the variations both in the objective and the subjective measures the correlation between these variations is also affected by the research conditions.

\subsection{Conclusion}

Pressure distribution appears to be the objective measure with the most clear association with the subjective ratings. This holds particularly for car seats, where a statistical relationship between pressure distribution and local discomfort has been reported. A uniform distribution at the seat pan as well as a high enough level of back pressure at the back rest at a lumbar level appear to be important in this respect. In office seats, only the correlation between lumbar pressure and local discomfort has been established. It is concluded that the incorporation of pressure measurements beside the rating of the subjective feelings of comfort and discomfort in the process of car seat design, would be valuable. It can be hypothesized that the same conclusion may hold for other seats (like office seats) as well, although the association between pressure distribution and (dis)comfort in other seats is yet to be determined.

For the other objective variables (posture, movement, muscle activity, spinal load), it is premature to state that measuring these variables would be useful in seat evaluation and design, for it is yet not clear whether and how these variables are associated with comfort or discomfort.

\section{Acknowledgements}

We acknowledge Koninklijke Ahrend NV for their support.

\section{References}

AnNett, J. 2002, Subjective rating scales: science or art? Ergonomics, 45, 966-987.

Armstrong, T. J., Buckle, P., Fine, L. J., Hagberg, M., Jonsson, B., Kilbom, A., Kuorinka, I. A. A., Silverstein, B. A., Suogaard, G. and Vilkari-Juntira, E. R. A. 1993, A conceptual model for work-related neck and upper limb disorders, Scandinavian Journal of Work, Environment and Health, 19, 73-84.

Bendix, T., Winkel, J. and Jensen, F. 1985, Comparison of office chairs with fixed forwards or backwards inclining or tiltable seats, European Journal of Applied Physiology, 54, 378 385.

Bishu, R. R., Hallbeck, M. S. and Riley, M. W. 1991, Seating comfort and its relationship to spinal profile: a pilot study, International Journal of Industrial Ergonomics, 8, 89-101.

Branton, P. 1969, Behaviour, body mechanics and discomfort, Ergonomics, 12, 316-327.

Eklund, J. A. E. and Corlett, E. N. 1987, Evaluation of spinal loads and chair design in seated work tasks, Clinical Biomechanics, 2, 27-33.

Floyd, W. F. and Roberts, D. F. 1958, Anatomical and physiological principles in chair and able design, Ergonomics, 2, 1-16.

Graf, M., Guggenbuhl, U. and Krueger, H. 1993, Investigations on the effects of seat shape and slope on posture comfort, and back muscle activity. International Journal of Industrial Ergonomics, 12, $91-103$.

Helander, M. G. and Zhang, L. 1997, Field studies of comfort and discomfort in sitting, Ergonomics, 40, 895-915.

Hertzberg, H. T. E. 1958, Seat comfort, in: R. Hansen, D. R. Cnrnog and H. T. E. Hertzberg (eds). Annotated Bibliography of Applied Physical Anthropology in Human Engineering, WADC Technical report 56-30, (Dayton, OH: Wright-Patterson Airforce Base), $297-$ 300 . 
Jensen, C. V. and Bendix, T. 1992, Spontaneous movements with various seated-workplace adjustments, Clinical Biomechanics, 7, 87-90.

Kamijo, K., Tsujimara, H., Obara, H. and Katsumatu, M. 1982, Evaluation of seating comfort. SAE Technical Paper Series 820761 (Troy, MI: Society of Automotive Engineers), 1-6.

Kleeman, W. 1981 The Challenge of Interior Design (Boston, MA: CBI).

Lee, K. S., Ferraiuolo, P. and Temming, J. 1993, Measuring Seat Comfort. SAE Technical Papers Series 930105 (Troy, MI: Society of Automotive Engineers), 25-30.

Lee, K. S., WAiker, A. M. and Wu, L. 1988, Physical stress evaluation of microscope work using objective and subjective methods, International Journal of Industrial Ergonomics, 2, 203-309.

LuEDER, R. K. 1983, Seat comfort: a review of the construct in the office environment, Human Factors, 25, 6, 701-711.

Mehta, C. R. and Tewari, V. K. 2000, Seating discomfort for tractor operators-a critical review, International Journal of Industrial Ergonomics, 25, 661-674.

Michel, D. P. and Helander, M. G. 1994, Effects of two types of chairs on stature change and comfort for individuals with healthy and herniated discs, Ergonomics, 37, 1231-1244.

Paul, R. D., Helander, M. G. and Morrow, J. 1997, Comfort and discomfort at work: the nurturing and pampering paradigm, in: P. Seppälä, T. Luopajärvi, C. H. Nygård and M. Matilla (eds). From experience to innovation. Proceedings of the 13th Triennial Congress of the International Ergonomics Association (Helsinki: Finnish Institute of Occupational Health) (Vol. 5), 504-506.

Richards, L. G. 1980, On the psychology of passenger comfort, in: D. J. Oborne and J. A Levis (eds), Human Factors in Transport Research (London: Academic Press) (Vol. 2), $15-23$.

Salewytsch, A. J. and Callaghan, J. P. 1999, Can quantified lumbar spine postures and trunk muscle activation levels predict discomfort during prolonged sitting? in Proceedings of the 31st Annual Conference of the ACE (on CD-rom).

Shackel, B., Chidsey, K. D. and Shipley, P. 1969, The assessment of chair comfort, Ergonomics 12, 269-306.

Slater, K. 1985, Human comfort (Springfield, IL: Thomas).

Thakurta, K., Koester, D., Bush, N. and Bachle, S. 1995, Evaluating short and long term seating comfort, in: SAE Technical Paper Series 950144 (Troy, MI: Society of Automotive Engineers), 33-37.

Tewari, V. K. and Prasad, N. 2000, Optimum seat pan and back-rest parameters form a comfortable tractor seat, Ergonomics, 43, 167-186.

Udo H., Fujimara, M. and Yoshinaga, F. 1999, The effect of a tilting seat on back, lower back and legs during sitting work, Industrial Health, 37, 369-381.

van DieËn, J. H., de Looze, M. P. and Hermans, V. 2001, Effects of dynamic office chairs on trunk kinematics, trunk extensor EMG and spinal shrinkage, Ergonomics, 44, 739-750.

Vergara, M. and Page, A. 2000, System to measure the use of the back rest in sitting-posture office tasks. Applied Ergonomics, 31, 247-254.

Wilder, D., Magnusson, M. L. and Pope, M. 1994, The effect of posture and seat suspension design on discomfort and back muscle fatigue during simulated truck driving, Applied Ergonomics, 25, 66-76.

WinKel, J. and JørGensen, K. 1986, Evaluation of foot swelling and lower-limb temperatures in relation to leg activity during long-term seated office work, Ergonomics, 29, 313-328.

Winkel, J. and WestgaARD, R. 1992, Occupational and individual risk factors for shoulderneck complaints: Part II-The scientific basis (literature review) for the guide, International Journal of Industrial Ergonomics, 10, 85-104.

Yun, M. H., Donges, L. and Freivalds, A. 1992, Using force sensitive resistors to evaluate the driver seating comfort, in S. Kumar (ed.), Advances in Industrial Ergonomics and Safety $I V$ (London: Taylor and Francis), 403-410.

Zhang, L., Helander, M. G. and Drury, C. G. 1996, Identifying factors of comfort and discomfort in sitting, Human Factors, 38, 377-389.

Zhon, J. H. and TANG, L. 1994, An evaluation of comfort of a bus seat, Applied Ergonomics, 25, 386-392. 
Copyright $\odot 2003$ EBSCO Publishing 